\title{
Human Capital, Unions and Productivity in a Labour-skilled \\ Sectoral Approach
}

This research paper aims to provide an empirical validation of the impact of human capital accumulation and labour market institutions on productivity growth. The primary objective of this study is to analyse economic and employment growth tendencies in the period between 1985 and 2007 in various OECD member countries. In our estimations we followed a specific taxonomy to identify the features of output per capita growth in different labour-skilled branches. Besides determining the sectoral differences of labour demand by standard comparative statistics, we used a dynamic panel regression method in our estimations to investigate the relationships between employment, human capital, labour institutions and output per capita. All in all, we were able to conclude that the high-skilled branches have achieved better economic growth performance than the lower-skilled ones in most of the OECD countries. Analysing the time series panel data of these countries our results also yield valid relationships between the level of education, labour unions and productivity growth in different branches.

Keywords: productivity growth, education, labour unions, sectoral approach

Journal of Economic Literature (JEL) codes: E25, J24, L16

\section{INTRODUCTION}

The contribution of labour to economic growth became especially popular in historical research after the rise of human capital theories advocated by Becker (1964) and Schultz (1961) and growth theories first formalised by Solow (1956). The notion of human capital arose out of the awareness that physical capital accumulation alone was not enough to explain long run economic growth. As Nakamura (1981:263) defines human capital as 'labour skills, managerial skills, and entrepreneurial and innovative abilities - plus such physical attributes as health and strength...', it is often implicitly referred to as formal and informal education. Later, many social indicators such as educational enrolments, average years of education and life expectancy became combined under the common term 'human capital'. However, it can also include such factors as the costs of raising children, health etc. (Földvári - Leeuwen 2007).

Meanwhile, the early years of 1970s and later the oil crisis eventually revealed that it takes more than just physical and human capital to generate economic growth. This made it possible to introduce institutions into new theories dealing with endogenous economic growth. But, unlike the neo-classical approach long-run economic growth should be determined within the models rather than being exogenously assumed (Czeglédi 2010). The perspective of endogenous growth theories also claimed that the most important mechanisms by which labour mar- 
ket institutions ${ }^{1}$ can affect productivity growth operate mainly through physical and human capital accumulation (Barro - Sala-i-Martin 1997). However, since then, serious debates have taken place in an attempt to explain the role of institutions. Although, as North (1991) claimed, institutions matter, essentially no clear theoretical consensus has yet emerged to answer how they might impact on productivity, nor what kind of characteristics they should have in economies.

The purpose of this research study aims to investigate the valid relationships between employment, human capital accumulation, institutions and productivity growth. In our hypothesis, we assumed that productivity growth varies in the performance of different labour-skilled employees. The rest of this paper is structured as follows. In the next sections we will briefly describe the features of output and employment growth with common descriptive statistics. In our estimations we followed a specific taxonomy to identify the characteristics of output and employment growth tendencies in different labour-skilled branches over the previous decade. Then we will demonstrate a dynamic regression model with cross-industry panel data in order to investigate how employment, the level of education, the unions etc. affects economic growth. The paper ends with some policy implications and a conclusion.

\section{THE DATABASES USED AND THE LABOUR-SKILLED TAXONOMY}

A unique database has been constructed for the analysis of economic and employment growth by the EU KLEMS (2003) Project. This project aims to create a database which include measures of economic growth, productivity, employment creation, capital formation and technological change etc. at the industry level for OECD countries from 1970 onwards. The last (March 2011) release of the KLEMS database provides data up to 2007 for a limited set of variables in different industries. Hence, in our estimations we should expend the given time series of gross value added ${ }^{2}$ (GVA) in constant (1995) prices and numbers of persons engaged in 56 separate industries ${ }^{3}$ between 1985 and 2007 to calculate productivity and employment growth. In our models we also need the sectoral share of investment within output for each OECD country, which is available from the Penn World Table (PWT) of Heston et al. (2006).

\footnotetext{
1 'Labour market institutions are a system of laws, norms or conventions resulting from a collective choice and providing constraints or incentives that alter individual choices over labour' according to Boeri - van Ours (2008).

${ }^{2}$ Gross value added (GVA) is a measure used in economics as the value of goods and services produced in an area, industry or sector. Gross value added is equivalent to the output (GDP) less the intermediate consumption.

${ }^{3}$ Industries were separated by Indicators of activities for Industry and Services, based on ISIC Rev 3.
} 
Economists generally work with relatively easy collectable datasets that consist of a large number of countries to reflect causality between education and economic growth. Therefore, one of the popular methods ${ }^{4}$ used to proxy human capital is the educational stock approach. An early example of this supplemented the human capital included in growth accounting exercises with such categories as age and education to account for the heterogeneity of labour (Denison 1967). Other research approaches are based on formal education i.e. enrolment ratios and literacy rates. For example, Ljungberg (2002) used historical data of enrolment and expenditure rates on education to look at this relationship in Sweden and Nunes (2003) considered the cyclical behaviour of government expenditure on education in Portugal. Marchand and Thélot (1997) estimated an index of human capital for France using an indicator of the number of actively employed and the quality of labour based on the productivity by average years of schooling. In our estimations we expend the average years of education over age of 25 from the PWT of GGDC (2014) database, as by Psacharopoulos (1994), and Barro and Lee (2013).

Using our dynamic model specification we establish the impacts of several available labour market institutions from the OECD (2014) database. The unions, the active labour market policies (ALMPs) and employment protection legislation (EPL) were tested as well. A large number of variables can help to determine and explain industrial growth performance. In our estimations we followed a specific taxonomy that was introduced by van Ark et al. (2003) to identify the features of productivity growth tendencies. This approach focused on general labour skills and was defined by educational attainment. However, the taxonomy distinguishes four groups, ranging from high to low-skilled intensive branches. The skill levels in Eurostat are based on the International Standard Classification of Education - 1976 (from ISCED 0 to 6). The table below lists the taxonomy of industries divided into four different groups by labour-skill:

\footnotetext{
${ }^{4}$ Parallel to the educational stock approach other and more comprehensive methods have also been developed. The cost based approach was firstly developed by Kendrick (1976) and takes all the costs of forming human capital into account separately (education, finance, food and health etc.). Another prospective approach is based on an idea of the human capital (HC) that is embodied in the future earnings of individuals. In this sense $\mathrm{HC}$ is valued as the total income that could be generated in the labour market over a lifetime (Le at al. 2003). Thus, some authors have tried to integrate the (dis)advantages of these approaches. For example, Dagum and Slottje (2000) equated the monetary value of a person's human capital with the average lifetime earnings of the population (weighted by the level of $\mathrm{HC}$ relative to the population).
} 
Table 1.

Skill taxonomy of total industry (with ISIC Rev 3.)

\begin{abstract}
1. High skilled (HS): Mineral oil refining, coke and nuclear fuel (23); Chemicals (24); Office machinery (30); Radio, television and communications equipment (32); Electronic valves and tubes (321); Telecommunication equipment (322); Radio and television receivers (323); Financial intermediation, except insurance and pension funding (65); Insurance and pension funding, except compulsory social security (66); Activities auxiliary to financial intermediation (67); Real estate activities (70); Computer and related activities (72); Research \& development (73); Other business services (74); Public administration and defence; compulsory social security (75); Education (80).
\end{abstract}

2. High-intermediate skilled (HIS): Medical, precision \& optical instruments (33); Scientific instruments (331); Other instruments (33-331); Other transport equipment (35); Building and repairing of ships and boats (351); Aircraft and spacecraft (353); Railroad equipment and transport equipment nec (352+359); Electricity, gas and water supply (40-41); Air transport (62); Supporting and auxiliary transport activities; activities of travel agencies (63); Communications (64); Renting of machinery \& equipment (71); Health and social work (85).

3. Low-intermediate skilled (LIS): Wood \& products of wood and cork (20); Pulp, paper \& paper products (21); Printing \& publishing (22); Fabricated metal products (28); Mechanical engineering (29); Electrical machinery and apparatus (31); Insulated wire (313); Other electrical machinery \& apparatus (31-313); Construction (45); Sale, maintenance and repair of motor vehicles and motorcycles; retail sale of automotive fuel (50); Wholesale trade and commission trade, except of motor vehicles and motorcycles (51); Retail trade, except of motor vehicles and motorcycles; repair of personal and household goods (52); Inland transport (60); Water transport (61).

4. Low skilled (LS): Agriculture (01); Forestry (02); Fishing (05); Mining and quarrying (10-14); Food, drink \& tobacco (15-16); Textiles (17); Clothing (18); Leather and footwear (19); Rubber \& plastics (25); Non-metallic mineral products (26); Basic metals (27); Motor vehicles (34); Furniture, miscellaneous manufacturing; recycling (36-37); Hotels \& catering (55); Other community, social and personal services (90-93).

Source: van Ark et al. (2003:60-61).

\title{
3. ECONOMIC AND EMPLOYMENT GROWTH SECTORAL TENDENCIES
}

The purpose of this section is to describe the labour demand structure of industries in the available 24 OECD countries. This section looks at the economic performance in the EU-15 contrasted with other OECD countries (Australia, Canada, Japan, Korea and the USA) during the period between 1985 to 2007, and the Visegrád Group (Czech Republic, Slovakia, Hungary and Poland) between 1995 and 2007. Our analysis begins with an examination of value added, which is one of the indicators most readily associated with increases in economic growth. Economic growth is defined here as the growth of Gross Value Added at constant (1995) prices. The average growth rates of value added in the four different labour-skilled branches of the examined countries are shown in Figure (1). 




Figure 1. Average economic growth rates of OECD countries, 1986-2007

Source: own calculation based on EC KLEMS (2014).

As Figure 1. suggests, the greatest growth of value added occurred in most of the highskilled (HS and HIS) and the smallest rate of output growth was typical in the low-skilled (LIS and LS) industries. Obviously, cross country variation ranged from 1 to 11 per annum. Although Figure 2. reflects the same output tendencies in Hungary in the period between 1995 and 2007, in some other Visegrád Group member states (namely Poland, the Czech Republic and Slovakia) there was a much larger proportion of value added growth in low-skilled industries than in the high-skilled ones. These countries are famous for the vigorous production of machinery and for vehicle engineering industries, which improved more markedly than the EU-15 averages of low-skilled (LS) branches.

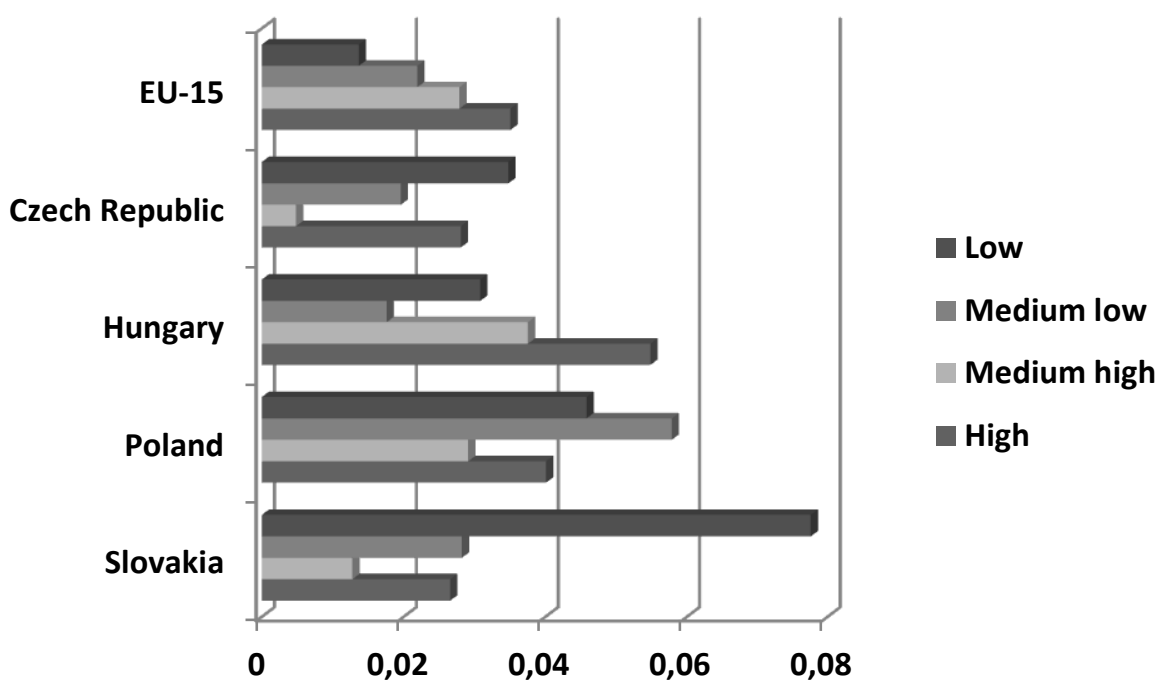

Figure 2. Average economic growth rates of EU-15 and Visegrád Group countries, 1996-2007 Source: own calculation based on EC KLEMS (2014). 
Figure 3. and 4. reflect employment growth rates in the same industries and time periods. The average annual employment growth rates in (HS) and (HIS) branches, in all examined OECD countries, were greater than in the lower skilled (LIS and LS) ones. This implies the increasing role of human capital in labour demand. Furthermore, employment growth was controversially negative in several OECD countries in the low-skilled (LS) industries. Thus, in the Visegrád Group it decreased more than the EU-15 averages. Meanwhile, we should also mention that probably thanks to the expansion of (LIS) branches in Hungary and Slovakia, the need for workers in these countries in the period between 1996-2007 was three or four times greater.

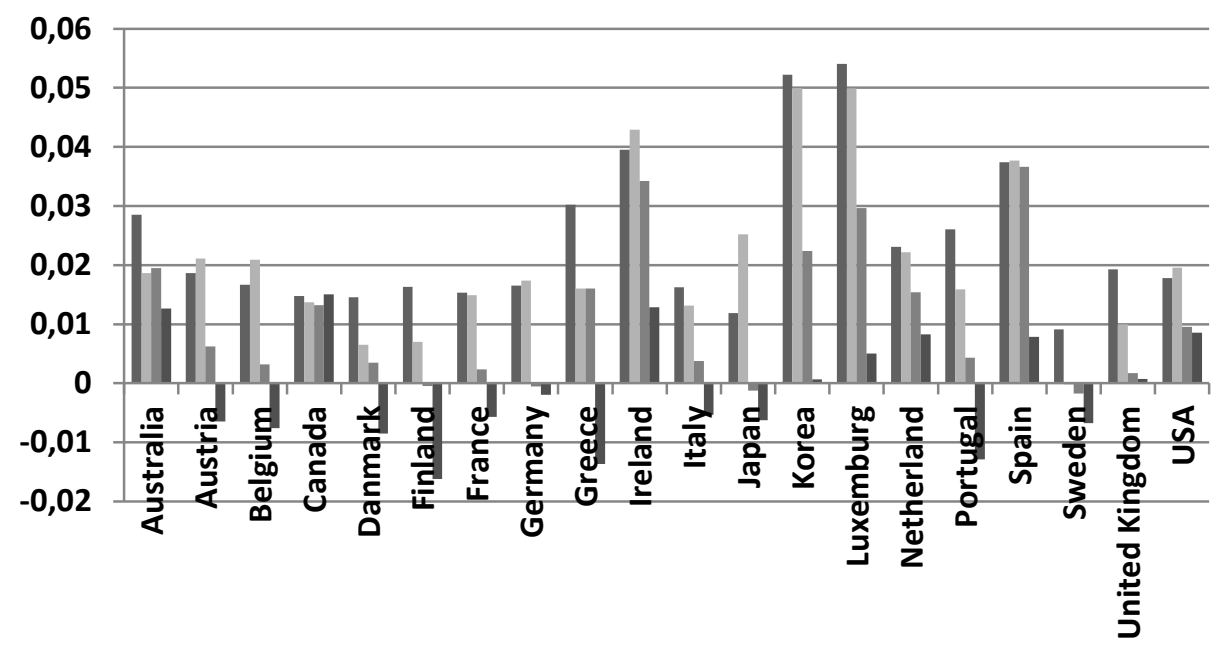

High Medium high $\square$ Medium low $\square$ Low

Figure 3. Average employment growth rates of OECD countries, 1986-2007 Source: own calculation based on EC KLEMS (2014).

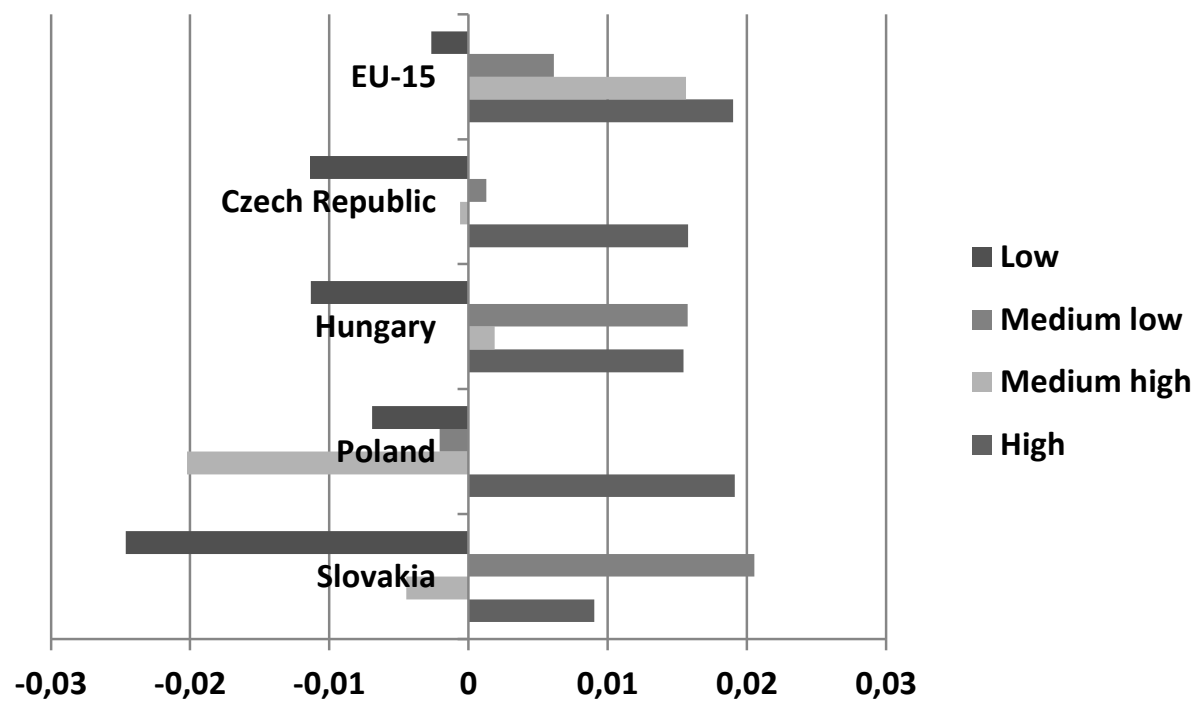

Figure 4. Average employment growth rates of EU-15 and Visegrád Group countries, 1996-2007 Source: own calculation based on EC KLEMS (2014). 
Industry structure should be described by using the distribution of output and employment within the aggregate level of each country. Table 2. represents the value added and the employment shares of the aggregate economic performances over two years. In the EU-15 countries in 1995 the highest proportion (38\%) of economic growth stemmed from (HS) sectors, and particularly by 2007, this branch also featured the greatest expansion (6\%). Although, in Hungary (38\%) and in Poland (25\%) the total distribution is less than the EU averages, we could conclude that the high-skilled branches have achieved better economic growth than the lower ones. The only exceptions are the Czech Republic and Slovakia, where the highest distributions in the (LIS) sectors were circa $40 \%$.

Table 2.

The output (GVA) and employment distribution (per annum) of EU-15 and Visegrád Group countries in each labour skilled sector, 1996-2007

\begin{tabular}{|c|c|c|c|c|c|c|c|c|}
\hline Sectors & \multicolumn{2}{|c|}{ HIGH } & \multicolumn{2}{|c|}{$\begin{array}{l}\text { MEDIUM } \\
\text { HIGH }\end{array}$} & \multicolumn{2}{|c|}{$\begin{array}{l}\text { MEDIUM } \\
\text { LOW }\end{array}$} & \multicolumn{2}{|c|}{ LOW } \\
\hline \multicolumn{9}{|c|}{ Output share (\%) } \\
\hline Country/Year & 1995 & 2008 & 1995 & 2008 & 1995 & 2008 & 1995 & 2008 \\
\hline Czech Republic & $28.80 \%$ & $25.99 \%$ & $15.65 \%$ & $10.63 \%$ & $30.71 \%$ & $39.34 \%$ & $24.84 \%$ & $24.05 \%$ \\
\hline Hungary & $35.74 \%$ & $38.44 \%$ & $12.70 \%$ & $11.25 \%$ & $25.64 \%$ & $29.24 \%$ & $25.92 \%$ & $21.07 \%$ \\
\hline Poland & $26.67 \%$ & $25.48 \%$ & $10.89 \%$ & $9.12 \%$ & $34.96 \%$ & $37.54 \%$ & $27.47 \%$ & $27.86 \%$ \\
\hline Slovakia & $31.58 \%$ & $23.12 \%$ & $14.48 \%$ & $8.62 \%$ & $31.63 \%$ & $39.71 \%$ & $22.31 \%$ & $28.55 \%$ \\
\hline EU-15 & $38.08 \%$ & $44.15 \%$ & $15.91 \%$ & $15.84 \%$ & $27.99 \%$ & $25.55 \%$ & $18.01 \%$ & $14.46 \%$ \\
\hline \multicolumn{9}{|c|}{ Employment share (\%) } \\
\hline Country/Year & 1996 & 2008 & 1996 & 2008 & 1996 & 2008 & 1996 & 2008 \\
\hline Czech Republic & $21.48 \%$ & $25.60 \%$ & $10.68 \%$ & $10.47 \%$ & $39.47 \%$ & $39.56 \%$ & $28.37 \%$ & $24.37 \%$ \\
\hline Hungary & $24.93 \%$ & $27.69 \%$ & $12.64 \%$ & $11.97 \%$ & $32.17 \%$ & $35.88 \%$ & $30.26 \%$ & $24.45 \%$ \\
\hline Poland & $19.40 \%$ & $24.79 \%$ & $12.51 \%$ & $9.93 \%$ & $30.12 \%$ & $29.77 \%$ & $37.97 \%$ & $35.51 \%$ \\
\hline Slovakia & $24.66 \%$ & $26.51 \%$ & $12.05 \%$ & $11.02 \%$ & $33.49 \%$ & $41.12 \%$ & $29.80 \%$ & $21.34 \%$ \\
\hline EU-15 & $28.77 \%$ & $31.58 \%$ & $14.12 \%$ & $15.08 \%$ & $33.44 \%$ & $32.07 \%$ & $23.67 \%$ & $21.27 \%$ \\
\hline
\end{tabular}

Source: own calculation based on EC KLEMS (2013).

When we estimated employment performance, the same tendencies in sectoral shifts also seemed to occur. Although, in the examined period the employment share of (HS) branches obviously increased and in (LS) sectors decreased in all EU-15 ${ }^{5}$ and Visegrád Group countries, in spite of the decreasing demand for low-skilled workers, there was increasing need for intermediate low-skilled (LIS) workers in Hungary (32\% increasing to circa 36\%) and Slovakia (from $33 \%$ to $41 \%$ ). These tendencies could be probably linked to the increasing role of machinery and engineering sectors in these countries.

\footnotetext{
${ }^{5}$ The EU-15 average increased in HS sectors from 28 to 44 per cent.
} 


\section{PRODUCTIVITY CHANGES: ECONOMETRIC EVIDENCE}

In the neo-classical growth models, developed from the 1950s by Solow (1956), no special attention was given to labour market institutions. Basically, it was argued that the growth of physical capital accumulation had an effect on the growth of GDP. Thus the unexplained determinant of this model, labelled Total Factor Productivity (TFP), could not be measured directly so it was approximated by the residual from growth accounting. This made it possible to introduce institutions into new theories dealing with endogenous economic growth. But, unlike the approach in the neo-classical model, long-run economic growth should be determined within the models rather than being exogenously assumed.

In the first human capital augmented models, pioneered by Lucas (1988), human capital was inserted as a factor of production similar to physical and labour accumulation. The consequence of this extension of the original Solow-model with human capital was that GDP growth was positively influenced by the growth of human capital. Human capital in this way exemplifies the skills, which are embodied in a worker. Hence, human capital is a rival good and excludable (Barro - Sala-i-Martin 2004). In another model, pioneered later by Romer (1990), the neo-classical growth model was followed in the sense that technological change causes long-run growth. Here, the effect of technological growth works on GDP growth through the level of human capital. In this case human capital produces new technologies directly because it is used as an input in $R \& D$ related activities and seen as the skills (knowledge and ideas) that are embodied in a worker. Consequently, in the latter case human capital is non-rival and partly-excludable. Although, most empirical results found that the effect of the accumulation of human capital on GDP growth seems to be noticeable, investment in capital goods, education, and technology alone will not produce economic growth (Gwartney et al. 1999). Furthermore, the effect of the growth of human capital on economic growth is usually reflected by low positive and significant coefficients (Barro - Lee 1993), (Cohen - Soto 2001), Krueger - Lindahl 2001) and (Portela et al. 2004), except in the famous study of Benhabib and Spiegel (1994).

Now, we begin by briefly reviewing what kind of relationship exists between productivity and human capital. First, we focus on a well-known human capital augmented implication, promoted by earlier Mankiw et al. (1992), for cross-county data. We assume a Cobb-Douglas production function, so production at time $[\mathrm{t}]$ can be written as:

$$
Y_{t}=\left(A_{t} L_{t}\right)^{1-\alpha-\beta} K_{t}^{\alpha} H_{t}^{\beta}
$$


The notation is the standard, where [Y] represents output, $[\mathrm{A}]$ is the level of TFP, $[\mathrm{K}]$ and [L] are capital and labour, and $[\mathrm{H}]$ is the stock of human capital. So, this equation shows how income depends on the accumulation of physical and human capital, technological growth and employment. Thus, we assume a constant return to scale and the magnitude of (1- $\alpha)$ should correspond roughly to the share of labour income in total GDP, which is close to $2 / 3$ in most countries.

According to the suggestion of Mankiw et al. there is an alternative way to express the role of institutions in this model. Firstly, divide output with the number of engaged workers and get [Y/L]. Essentially, the logarithm of output per capita implies the steady state level of productivity. Also use the rate of investment in physical capital $\left[\mathrm{s}_{\mathrm{k}}\right]$ and the employment growth $[\mathrm{n}]$ in logs. We also assume that $[\mathrm{g}]$ and $[\delta]$ are constant across countries, because $[\mathrm{g}]$ primarily reflects the advancement of knowledge and there is no reason to expect depreciation rates $[\delta]$ to vary greatly across countries. Thus, $[\mathrm{h}]$ represents the average years of schooling as a proxy of human capital. Let $\ln [\mathrm{A}]=[\mathrm{X}]$, which, in this model, is a vector that captures the impact of institutions and [e] represents country-specific shocks. Hence, the log income per capita at a given time $[\mathrm{t}]$ is equal to the following:

$$
\ln \left(\frac{Y}{L}\right)_{t}=\frac{\alpha}{1-\alpha} \ln \left(s_{k}\right)_{t}-\frac{\alpha}{1-\alpha} \ln (n+g+\delta)_{t}+\frac{\beta}{1-\alpha} \ln (h)+\frac{\alpha}{1-\alpha} \ln (X)_{t}+\varepsilon_{t}
$$

At the moment, the model of Equation 2. is fundamentally a steady-state version of the traditional Solow-model and it should only be related to the level and not the growth of income. Meanwhile, a channel for the impact of industrial structure on aggregate economic growth refers to the indirect effects that might be generated by positive externalities between industries. The higher aggregate income also allows for more public and private investment in complementary institutions, e.g. for research and education etc., (Peneder 2002). The descriptive analysis could only detect the direct contribution to aggregate growth performance of structural shifts at the industry level. Hence, many economic models suggest that current economic performance depends upon past behaviour including as elements persistence, partial adjustment, etc. (Verbeck 2001). Therefore, we estimate a dynamic model specification in a sectoral approach to capture the importance of measuring the indirect effects, which is why we must implement the lag structures of the variables in our econometric analysis.

After having demonstrated the existence of a systematic relationship between the industrial structure of labour demand and income level, we will now examine the impact of education level and labour market institutions on economic growth per capita. Taking into account new endogenous growth theories, our model includes the lagged dependent variables among the 
repressors. A dynamic specification requires the special instrumentation of the empirically offered GMM estimators, developed by Arellano and Bond (1991). Although, theoretically the two-step estimators should be preferred (Windmeijer 2005), because of the empirical problems of the downward biased standard errors, the one-step estimators were used in our calculations. These methods employ lagged levels of the dependent and predetermined variables, as well as differences between the exogenous variables as instruments.

In our dynamic model the economy tends toward long run equilibrium. The extent of economic growth generally affects the rate at which per capita output approaches its steady state value. After taking the first differences of Equation 2, our basic model assumes the following formula, which is tested in each of the different labour-skilled sectors:

$$
\begin{aligned}
& \Delta \ln Y_{i t}=\beta_{o}+\beta_{1} \Delta \ln Y_{i t-1}+\beta_{2} \ln \left(s_{k}\right)_{i t}+\beta_{3} \ln (n+g+\delta)_{i t}+\beta_{4} \ln (h)_{i t}+\beta_{5} \ln (U N)_{i t}+ \\
& +\beta_{6} \ln (A L M P)_{i t}+\beta_{7} \ln (E P L)_{i t}+e_{i t}
\end{aligned}
$$

Note: $\Delta v a r$ - variable in first differences, $\Delta v r_{t-1}$ - lagged differences, $\ln$ - in logarithm.

The variables refer to the following. The independent variable here is the ratio of a real GVA per capita of country [i] for the period [t] at a constant price (1995). The first independent variable is the first lag of the productivity growth $\left[\mathrm{Y}_{\mathrm{i}, t}\right]$. $\left[\mathrm{s}_{\mathrm{k}}\right]$ is the share of investment within sectoral output and $[\mathrm{n}]$ is the average growth rate of labour forces in each branch. The rate of $[\mathrm{g}]$ and depreciation $[\delta]$ is here assumed to be 0.05 , as in Mankiw et al. (1992). The [h] variable $^{6}$ indicates the average level of education over zhe age of 25 and [UN] captures the density of labour market unions from the OECD (2014) database. ${ }^{7}$ The trade union density corresponds to the ratio of wage and salary earners that are trade union members, divided by the total number of workers engaged in each sector. ALMPs measured as a percentage of sectoral GDP refers to the labour market policies. Currently ALMPs aim to improve the functioning of the labour market by enhancing and facilitating the mobility and adjustment, etc. of workers. Employment protection legislation (EPL) is a set of mandatory restriction governing the dismissals of employees (Boeri et al. 1999). Their main purpose is to increase the volume and stability of employment. Essentially, EPL regulations may affect the equilibrium level of employment and productivity growth. Finally, [e] is the error term. The first lags of the dependent variables were used as instruments in our model specifications. The estimations are based upon a data panel comprising $i=24$ OECD countries over a period of $t=22$ years (1985 2007).

\footnotetext{
${ }^{6} \mathrm{We}$ assumed here that the level of human capital (one of the main characteristics of labour supply) was given as a cross-country specific variable for each branch.

${ }^{7}$ Of the examined institutions only the labour unions have significant z-statistics.
} 
Table 3 represents the corresponding estimation results for the one-step GMM methods of our dynamic model discussed above. At the bottom section of the table we demonstrate the common results of $\mathrm{AR}(1)$ tests to identify autocorrelation and the Sargan-Hansen tests of over-identifying restrictions. The significance levels of the tests in all models suggest that the dynamic specification should be preferred.

Table 3.

Dynamic panel regression of real GDP (GVA) per capita, 1985-2007

\begin{tabular}{|c|c|c|c|c|c|c|c|c|}
\hline \multicolumn{9}{|c|}{ Dependent variable: $\Delta \ln (Y)_{\text {it }}$} \\
\hline $\begin{array}{l}\text { Independent } \\
\text { Variables/ } \\
\text { Sectors }\end{array}$ & High (HS) & High (HS) & $\begin{array}{c}\text { Medium } \\
\text { high } \\
\text { (HIS) }\end{array}$ & $\begin{array}{c}\text { Medium } \\
\text { high } \\
\text { (HIS) }\end{array}$ & $\begin{array}{c}\text { Medium } \\
\text { low } \\
\text { (LIS) }\end{array}$ & $\begin{array}{c}\text { Medium } \\
\text { low } \\
\text { (LIS) }\end{array}$ & $\begin{array}{l}\text { Low } \\
\text { (LS) }\end{array}$ & $\begin{array}{l}\text { Low } \\
\text { (LS) }\end{array}$ \\
\hline \multirow[t]{2}{*}{$\operatorname{constant}^{\mathrm{a}}$} & 1.556 & 1.579 & 2.175 & 2.21 & 2.746 & 2.74 & 4.77 & 5.01 \\
\hline & $(6.77)^{* * *}$ & $(6.83)^{* * *}$ & $(9.41)^{* * *}$ & $(5.26)^{* * *}$ & $(9.06)^{* * * *}$ & $(4.82)^{* * * *}$ & $(7.89)^{* * * *}$ & $(8.22)^{* * *}$ \\
\hline \multirow[t]{2}{*}{$\Delta \ln (\mathbf{Y})_{\mathrm{it}-1}{ }^{\mathrm{a}}$} & -0.122 & -0.113 & -0.027 & -0.025 & 0.013 & 0.016 & -0.138 & -0.139 \\
\hline & $(-1.91)^{*}$ & $(-1.77)^{*}$ & $(-0.47)$ & $(-0.24)$ & $(-0.2)$ & $(-0.19)$ & $(-2.26)^{* *}$ & $(-2.3)^{* *}$ \\
\hline \multirow[t]{2}{*}{$\ln \left(s_{k}\right)_{i t}^{a}$} & 0.009 & 0.009 & 0.029 & 0.03 & 0.184 & 0.183 & 0.174 & 0.18 \\
\hline & $(-0.33)$ & $(-0.31)$ & $(-0.94)$ & $(-1.02)$ & $(5.49)^{* * * *}$ & $(4.92)^{* * * *}$ & $(5.06)^{* * *}$ & $(5.25)^{* * * *}$ \\
\hline \multirow{2}{*}{$\ln \left(\mathbf{n}_{\mathrm{i}}+\mathrm{g}+\boldsymbol{\delta}\right)_{\mathrm{t}}^{\mathrm{a}}$} & -0.267 & -0.27 & -0.403 & -0.41 & -0.46 & -0.458 & -0.645 & -0.675 \\
\hline & $(-6.25)^{* * *}$ & $(-6.31)^{* * *}$ & $(-9.17)^{* * *}$ & $(-6.33)^{* * * *}$ & $(-9.51)^{* * *}$ & $(-6.05)^{* * *}$ & $(-8.11)^{* * * *}$ & $(-8.44)^{* * *}$ \\
\hline \multirow{2}{*}{$\ln (\mathbf{h})_{\mathrm{it}}{ }^{\mathrm{a}}$} & 0.516 & 0.549 & 0.54 & 0.565 & 0.282 & 0.302 & -0.345 & -0.33 \\
\hline & $(4.88)^{* * *}$ & $(5.19)^{* * *}$ & $(4.99)^{* * * *}$ & $(3.72) * * *$ & $(3.83)^{* * *}$ & $(3.28)^{* * * *}$ & $(-4.1) * * *$ & $(-3.99) * *$ \\
\hline \multirow{2}{*}{$\ln (\mathbf{U N})_{\mathrm{it}}{ }^{\mathrm{a}}$} & & -0.01 & & -0.006 & & -0.007 & & -0.015 \\
\hline & & $(-2.13)^{* *}$ & & $(-3.03)^{* * *}$ & & $(-3.88)^{* * *}$ & & $(-2.69)^{* * * *}$ \\
\hline $\begin{array}{l}\text { Number of } \\
\text { observations }\end{array}$ & \multicolumn{8}{|c|}{438} \\
\hline $\begin{array}{l}\text { Number of } \\
\text { countries }\end{array}$ & \multicolumn{8}{|c|}{24} \\
\hline $\begin{array}{l}\text { Number of } \\
\text { instruments }\end{array}$ & 24 & 25 & 24 & 25 & 24 & 25 & 24 & 25 \\
\hline Wald-test $^{b}$ & $49.24 * * *$ & $52.91 * * *$ & $94.76 * * *$ & $49.85 * * *$ & $95.11 * * *$ & $86.57 * * *$ & $87.41 * * *$ & $94.73 * * *$ \\
\hline $\operatorname{AR}(1)$-test $^{\mathrm{a}}$ & $(-2.83)^{* * * *}$ & $(-2.79)^{* * * *}$ & $(-2.43)^{* *}$ & $(-2.41)^{* *}$ & $(-3.45)^{* * *}$ & $(-3.47)^{* * *}$ & $(-3.45)^{* * *}$ & $(-3.35)^{* * * *}$ \\
\hline Sargan-test $^{b}$ & $65.95 * * *$ & $67.62 * * *$ & $42.9 * * *$ & $42.63 * * *$ & $55.11 * * *$ & $54.77 * * *$ & $47.87 * * *$ & $44.61 * * *$ \\
\hline
\end{tabular}

Source: own calculation based on EC KLEMS (2014), OECD (2014) and Heston et al. (2006) databases.

Notes: ${ }^{a}$ Heteroscedasticity robust z-statistics are in parentheses. ${ }^{\mathrm{b}}$ Over-identifying restrictions valid chi-squares. Letters in the upper index refer to significance: ***: significance at 1 per cent, **: 5 per cent, *: 10 per cent. Pvalues without an index mean that the coefficient is not significant even at the 10 per cent level. 
The impact of the lagged GVA per capita (Y), however, is not robust in the intermediate high and low-skilled (HIS and LIS) sectors ${ }^{8}$, although in the other branches there are significant positive z-statistics. As a consequence, an increase in the share of investment within the GDP $\left[\mathrm{s}_{\mathrm{k}}\right]$ variable, as theoretically expected, we could claim a positive (pro-cyclical) impact on productivity growth in both sectors. Meanwhile, according to growth theories, employment growth attainment is negatively related to the growth of per capita output in the long run. Thus, the coefficients ranged from circa $-0.26 \%$ to $-0.67 \%$. Obviously, if employment is increased the high-skill intensive (HS) branches may have affected productivity least of all.

In this table we find that there is a valid dynamic representation of the relationship between the measure of human capital and productivity growth. The effect of a $1 \%$ increase in the level of human capital results in an increase in the growth of GDP per capita of 0.3 percentage point in HS sectors (0.5 in HIS and 0.2 in LIS branches). Nevertheless, in the LS branches, there is a significant negative (-0.3) coefficient. Hence, human capital is controversially correlated with productivity growth in these low skilled sectors.

Using our dynamic model specification of Equation 3 we establish the impacts of different labour market institutions from the OECD (2014) database. All in all, we want to know whether there are existing labour market institutions which could impact economic growth per capita. Although, the minimum wages, the active labour market policies (ALMPs), and the employment protection legislation (EPL) were tested as well, only the labour unions (UN) have significant statistics (see Tables 3 and 4).

Labour (or trade) unions are voluntary membership organizations that represent the interests of their members. Increasingly at the beginning of the twentieth century they became national organizations aiming to include all workers and to have a greater political role. Because of workers' interests unions are not only interested in wages but also the number of employees. There are two avenues of research in the empirical literature on the effects on unions to the labour market. Some research has estimated the effects of unions on members' wages visà-vis non-members, while others have dealt with the effects of union density and bargaining coordination on employment and inflation (Cahuc - Zylbelberg 2010). Thus, Ebbinghaus and Wisser (2000) also reported that the 'de-unionization' was concentrated mostly in AngloSaxon countries, where union density in the non-market oriented sectors was five times higher than in market economies. These facts confirm that an increase in union density reduces employment in these sectors.

\footnotetext{
${ }^{8}$ Lack of significance means in this sense that the lagged dependent variable does not indicate productivity growth in this branch at given level of output per capita and other determinants.
} 
Table 4.

Dynamic panel regression of real GDP (GVA) per capita, 1985-2007

\begin{tabular}{|c|c|c|c|c|}
\hline \multicolumn{5}{|c|}{ Dependent variable: $\Delta \ln (Y)_{\text {it }}$} \\
\hline Independent & & Medium & Medium & Low \\
\hline Variables/ & High (HS) & high & low & $(\mathbf{L S})$ \\
\hline Sectors & & (HIS) & (LIS) & \\
\hline \multirow[t]{2}{*}{ constant $^{\mathrm{a}}$} & 1.89 & 2.31 & 2.83 & 4.4 \\
\hline & $(6.63)^{* * *}$ & $(7.63)^{* * *}$ & $(8.06)^{* * *}$ & $(7.13)^{* * *}$ \\
\hline \multirow{2}{*}{$\Delta \ln (\mathbf{Y})_{\mathrm{it}-1}^{\mathrm{a}}$} & -0.159 & -0.092 & -0.005 & -0.196 \\
\hline & $(2.31)^{*}$ & $(-1.35)$ & $(-0.08)$ & $(-3.13)^{* *}$ \\
\hline \multirow[t]{2}{*}{$\ln \left(s_{k}\right)_{i t}{ }^{a}$} & 0.012 & 0.015 & 0.162 & 0.131 \\
\hline & $(0.41)$ & $(1.02)$ & $(4.38)^{* * *}$ & $(3.63)^{* * *}$ \\
\hline \multirow[t]{2}{*}{$\ln \left(n_{i}+g+\delta\right)_{t}^{a}$} & $-\mathbf{0 . 3 2}$ & -0.414 & -0.461 & -0.598 \\
\hline & $(-6.29)^{* * *}$ & $(-7.55)^{* * *}$ & $(-3.72)^{* * *}$ & $(-7.18)^{* * *}$ \\
\hline \multirow{2}{*}{$\ln (h)_{i t}{ }^{a}$} & 0.539 & 0.562 & 0.305 & -0.179 \\
\hline & $(4.72)^{* * *}$ & $(4.56)^{* * *}$ & $(3.72)^{* * *}$ & $(-2.05)^{* *}$ \\
\hline \multirow{2}{*}{$\ln (\mathbf{A L M P})_{\mathrm{it}}$} & 0.009 & -0.012 & 0.009 & -0.021 \\
\hline & $(1.00)$ & $(-1.09)$ & $(0.06)$ & $(-1.25)$ \\
\hline \multirow{2}{*}{$\ln (E P L)_{i t}{ }^{a}$} & 0.009 & 0.007 & 0.002 & -0.006 \\
\hline & $(0.28)$ & $(0.19)$ & $(0.08)$ & $(-0.24)$ \\
\hline Number of observations & \multicolumn{4}{|c|}{371} \\
\hline Number of countries & \multicolumn{4}{|c|}{24} \\
\hline Number of instruments & \multicolumn{4}{|c|}{26} \\
\hline Wald-test $^{\text {b }}$ & $50.74 * * *$ & $66.35 * * *$ & $79.48 * * *$ & $78.12 * * *$ \\
\hline $\operatorname{AR}(1)-$-test $^{\mathrm{a}}$ & $(-2.33)^{* * *}$ & $(-2.45)^{* * *}$ & $(-3.17)^{* * *}$ & $(-2.90)^{* * *}$ \\
\hline Sargan-test ${ }^{\mathbf{b}}$ & $85.36^{* * *}$ & $38.05^{* * *}$ & $48.81 * * *$ & $35.39 * * *$ \\
\hline
\end{tabular}

Source: own calculation based on EC KLEMS (2014), OECD (2014) and Heston et al. (2006) databases. Notes: ${ }^{a}$ Heteroscedasticity robust z-statistics are in parentheses. ${ }^{\mathrm{b}}$ Over-identifying restrictions valid chi-squares. Letters in the upper index refer to significance: ***: significance at 1 per cent, **: 5 per cent, *: 10 per cent. Pvalues without an index mean that the coefficient is not significant even at the 10 per cent level.

As we can see from our results, the effect of unions on the growth of productivity does not seem to be large. The effect of a $1 \%$ increase in the level of union density results in a decrease in the growth of GDP per capita was ranged between minus 0.07 and 0.15 percentage points in each sector. Nevertheless, there are negative coefficients in all branches, so labour unions are obviously controversially correlated with productivity growth in both of the sectors.

Although, there is no significant relationship between ALMP, EPL and economic growth per capita in our dynamic model specification, several additional research directions have emerged in this study. First, (1) we argue that the human capital theoretical perspective is relevant since it extends the achievements and the existing frontiers of macroeconomic and 
growth theories. These approaches stated that labour highly correlated with output growth in the long run, but they also emphasized human capital as an originating source of economic growth. Hence, the impact of primary, secondary and tertiary levels of education on productivity could be measured from this point of view. However (2), our empirical findings could only demonstrate the relationship between labour unions and productivity growth, since yet there is no unambiguous evidence to identify the impact of other institutions (i.e. unemployment benefits, minimum wages, tax wedges etc.) on output per capita in different labourskilled sectors. Thus, labour market institutions never operate in isolation. Hence, their employment effects interact with those of other institutions, so we should later examine all of them. Hopefully, our future research using these approaches could be fruitful as well.

\section{Conclusion}

In this paper we had two objectives. Our first objective was to analyse economic and employment growth tendencies for the period 1985-2007 in various OECD states. From our results we were able to claim that the greatest growth of value added in most of the OECD countries occurred in industries classified as high-skilled (HS and HIS) and the smallest rate of growth was typical in the low-skilled (LIS and LS) sectors. The average annual employment growth rates in (HS) and (HIS) branches, in all examined OECD countries, were greater than in the lower skilled (LIS and LS) ones. This implies the increasing role of human capital in labour demand. In the EU-15 countries the highest proportion of economic growth stemmed from the (HS) sectors, and the employment share in these branches was obviously increased, but in the (LS) sectors it decreased in the Visegrád Group countries as well.

The second objective was to examine the impact of human capital and labour market institutions on economic growth per capita. Our dynamic panel regression model yields a valid positive relationship between the level of education and productivity growth in the HS, HIS and LIS sectors, the only exception being the LS branch. We could also claim that union density is also negatively correlated with productivity growth in each sector.

As a consequence, we can consider the following government policies from our model representation. Given that mainstream macro policies aim to promote stable long run economic growth, we could recommend assisting the high-skilled employment branches if this affects the basic economic demand structure. In particular, our analysis suggests that policy makers must try to increase the degree of competition in labour markets; i.e. by motivating skilled workers to learn more for better productivity growth. Moreover, we believe that a lower density of labour unions is needed for better economic performance. 


\section{Acknowledgement}

This research was realized in the frames of TÁMOP 4.2.4. A/2-11-1-2012-0001 „National Excellence Program - Elaborating and operating an inland student and researcher personal support system" The project was subsidized by the European Union and co-financed by the European Social Fund.

\section{REFERENCES}

Arellano, M. - Bond, S. (1991): Some Tests of Specification for Panel Date: Monte Carlo Evidence and an application to Employment Equations, Review of Economic Studies, 58: $277-297$.

van Ark, B. - Robinson, C. - Stokes, L. - Stuivenwold, E. (2003): Industry Structure and Taxonomies, 37-72, in O'Mahony, M. - van Ark, B. (ed.) EU productivity and competitiveness: An industry perspective. Can Europe resume the catching-up process? EC, Italy.

Barro, R. J. - Sala-i-Martin, X. (1997): Technological Diffusion, Convergence, and Growth. Journal of Economic Growth, 2(1): 1-27. (2004): Economic Growth, Cambridge, The MIT Press.

Barro, R. J. - Lee, J. W. (1993): Institutional comparisons of educational attainment, Journal of Monetary Economics, 32(3): 363-394.

(2013): Educational Attainment Dataset, (last downloaded:

2013.10.16.) http://www.barrolee.com/

Becker, G. S. (1964): Human Capital, New York. NBER Press.

Benhabib, J. - Spiegel, M. M. (1994): The Role of Human Capital in Economic Development: Evidence from Aggregate Cross-Country and Regional U.S. Data, Journal of Monetary Economics, 34(2): 143-173.

Boeri, T. - van Ours, J. (2008): The Economics of Imperfect Labour Markets, Princeton University Press. New Yersey.

Boeri, T. - Nicoletti, G. - Scarpetta, S. (1999): Regulation and Labour Market Performance, GIER Working Paper No. 158.

Cahuc, P. - Zylberberg, A. (2010): Labor Economics, Cambridge MIT Press, London.

Czeglédi, P. (2010): Individual Rights as a Factor of Economic Convergence, Acta Oeconomica, 60(4): 375-403. 
Dagum, C. - Slottje, D. J. (2000): A new method to estimate the level and distribution of household human capital with application, Structural Change and Economic Dynamics, (11):67-94.

Denison, E. F. (1967): Why Growth Rates Differ: Postwar Experience in nine Western Countries, The Brookings Institution Press, Washington, D.C.

Ebbinghaus, B. - Wisser. J (2000): Trade Unions in Western Europe since 1945. London, UK, Palgrave-Macmillan Press.

EC (2014): EU KLEMS Database, http://www.euklems.net/ (last download: 2013. 08. 16.)

Földvári, P. - van Leeuwen, B. (2008):Human capital and economic growth in Asia 18902000: a time-series analysis, Asian Economic Journal, 22(3): 225-240.

GGDC (2014): Penn World Table 8.0, (last download: 2014. 11. 12.) http://citaotest01.housing.rug.nl/FebPwt/Dmn/AggregateXs.mvc/PivotShow

Gwartney, J. - Lawson, R. - Holcombe, R. G. (1999): Economic Freedom and The Environment for Economic Growth. Journal of Institutional and Theoretical Economics, 155(4): $643-663$.

Heston, A. - Summers, R. - Aten, B. (2006): Penn World Table Version 6.2., Center for International Comparisons of Production, Income and Prices at the University of Pennsylvania.

Kendrick, J. W. (1976): The Formation and Stocks of Total Capital. New York: Columbia University Press for NBER.

Krueger, A. B. - Lindahl, M. (2001): Education for Growth: Why and For Whom?, Journal of Economic Literature, 39(4): 1101-1136.

Le, T. - Gibson, J. - Oxley, L. (2003): Cost- and Income-based measures of Human Capital, Journal of Economic Surveys, 17(3): 271-307.

Ljungberg, J. (2002): About the Role of Education in Swedish Economic Growth, Historical Social Research, 27(4): 125-139.

Lucas, Jr, R. E. (1988): On the Mechanics of Economic Development. Journal of Monetary Economics, 22(1): 3-42.

Mankiw, G. N. - Romer, P. M. - Weil, D. N. (1992): A Contribution to the Empirics of Economic Growth, The Quarterly Journal of Economics, 107(2): 407-437.

Marchand, O. - Thélot, C. (1997): Formation de la main d'oevre et capital humain en France depuis deux siècles, 'Les dossiers Éducation et Formations, (80), ministère de l'Éducation nationale, de l'Enseignement supérieur et de la Recherche, DEP. 
Nakamura, J. I. (1981): Human Capital Accumulation in Premodern Rural Japan, The Journal of Economic History, 41(2): 263-281.

North, D. C. (1991): Institutions, Institutional Change, and Economic Performance, Cambridge University Press, Cambridge.

Nunes, A. B. (2003): Government Expenditure on Education, Economic Growth and Long Waves: The Case of Portugal, Paedagogica Historica, 39(5): 559-581.

OECD (2014): OECD Stat Database, http://stats.oecd.org/Index.aspx?DatasetCode=RHMW , (last downloaded: 2014. 01.16.)

Portela, M. - Alessie, R. - Teulings, C. (2001): Measurement Error in Education and Growth Regressions, Scandinavian Journal of Economics, 112(3): 618-639.

Psacharopoulos, G. (1994): Returns to investment in education: A global update, World Development, Elsevier, 22(9): 1325-1343.

Romer, P. (1990): Endogenous Technological Change, Journal of Political Economy, 98(5): 71-102.

Sargan, J. (1958): The estimation of economic relationships using instrumental variables. Econometrica, 26(3): 393-415.

Schultz, T. (1961): Investment in Human Capital, American Economic Review, 51(1): 1-17.

Solow, R. M. (1956): A Contribution to the Theory of Economic Growth. The Quarterly Journal of Economics, 70(1): 65-94.

Verbeek, M. (2001): A Guide to Modern Econometrics, John Wiley and Sons.

Windmeijer, F. (2005): A finite sample correction for the variance of linear efficient two-step GMM estimators, Journal of Econometrics, Elsevier, 126(1): 25-51. 